\title{
Elementos para el análisis de la reforma electoral de 2014
}

\author{
Leonardo Valdés Zurita* \\ Patricia González Suárez
}

\section{Sumario:}

I. Introducción

II. El sistema electoral mexicano y sus reformas

III. La reforma electoral de 2007-2008

IV. La nueva reforma electoral de 2013-2014

V. Bibliografía

* Investigador asociado en El Colegio de México; ex consejero presidente del IFE. 


\section{Resumen:}

Este artículo ofrece un breve recorrido de las reformas político-electorales para arribar a la evaluación de la reforma electoral 2007-2008 y compararla con la reforma al artículo 41 de la Constitución Política de Estados Unidos Mexicanos y la nueva legislación, la Ley General de Instituciones y Procedimientos Electoral y Ley de Partidos Políticos promulgadas en 2014.

\section{Abstract:}

This paper offers a concise review of mexican political-electoral reforms. It presents an evaluation of the 2007-2008 reform. And compares it with the constitutional reform, and the new laws for Institutions and Electoral Procedures and for Political Parties, enacted in 2014.

Palabras claves: sistema electoral, reforma electoral, partidos políticos, Instituto Federal Electoral, Instituto Nacional Electoral, organismos públicos locales.

Key words: electoral system, electoral reform, political parties, Instituto Federal Electoral, Instituto Nacional Electoral, local public entities. 


\section{Introducción}

En México tenemos una larga experiencia en la realización de procedimientos legislativos que tienen como fin modificar las normas que gobiernan los procesos de conformación de nuestros órganos de gobierno y de representación política. Las reformas políticas han sido el espacio para el desarrollo de las reglas a partir de las cuales se disputa el poder político en este país. Por eso, generan pasión e, incluso, situaciones de alta confrontación.

Por ese motivo, las propias reformas político electorales pueden ser observadas como procesos políticos en sí mismos. ${ }^{1}$ Así se entiende cómo, a principios de los años cincuenta del siglo pasado, se desató una intensa polémica al interior del partido en el gobierno, respecto de la pertinencia de otorgar el voto a las mujeres. Muchos sabían que no podían retrasar más el reconocimiento de un derecho ciudadano, que se extendía en todos los países considerados como democráticos en ese momento. Pero también muchos de ellos temían que la participación electoral de las mujeres fortaleciera a la oposición conservadora y, en esa medida, debilitarán la consolidación de un sistema de partido hegemónico; que se empezaba a acostumbrar a ganar "de todas, todas".

Una década después, una parte de la oposición empezaba a cansarse de acudir a elecciones que estaban perdidas desde antes de realizarse. El arrastre social de partido de la Revolución y la falta de equidad en las reglas de la competencia producían elecciones sin opción, en las que las oposiciones se consolidaban como "nacidas, para perder". Por eso se reformó la Constitución, para crear los diputados de partido, esos que la oposición obtenía, por su porcentaje de votación, aún sin haber ganado ningún distrito. ${ }^{3}$

Luego de la tragedia de 1968, no solo se redujo la edad para votar (de 21 a 18 años), sino que se llevó a cabo la elección típica del sistema de partido hegemónico que, además, llevó a muchos a aceptar que era necesario cambiar. Claro que no faltaron los que pensaron que era posible "cambiar, para que todo siga igual". Lo cierto es que la reforma política posterior a las elecciones de 1976, cambió de manera significativa la operación del

\footnotetext{
1 Véase, entre otros, Renwick (2010) y Bowler and Donovan (2013).

2 Véase Tuñón (2002).

3 Véase Molinar (1993).
} 
sistema electoral y empezó a mezclar los ingredientes en los que se "cocinó" el fin del partido hegemónico.

La elección presidencial de 1988 llevó "a punto" ese proceso. La salida de un grupo de dirigentes del partido hegemónico; el desempeño electoral de la alianza conformada por cuatro partidos de izquierda; la nueva conformación del Congreso, sin mayoría absoluta para el partido del presidente, y la disposición del mayor partido de la oposición, dieron paso a un nuevo proceso de reforma política. Las reglas negociadas a principios de la década y perfeccionadas con la reforma de 1996, sirvieron para dar cause a la consolidación de un sistema plural de partidos, que compiten en condiciones de equidad por el poder político.

No obstante, ese marco reglamentario no fue suficiente para otorgar certeza al resultado de una elección presidencial altamente competida. Por eso, después de la elección de 2006 fue necesaria una nueva reforma que incrementó significativamente la equidad en la competencia e instauró procedimientos para verificar el resultado de una nueva elección "muy cerrada". Con esas reglas renovadas se renovó la Cámara de Diputados en 2009 y en 2012. En este último, se eligió además la totalidad de los miembros del Senado y al presidente de la República.

Un nuevo ciclo de reforma política concluyó. Empezó cuando el presidente y los dirigentes de los principales partidos políticos firmaron el Pacto por México y establecieron las líneas de trabajo de ese proceso. El objetivo principal fue llevar los niveles de equidad y certeza que se han alcanzado en las elecciones federales al ámbito local. No era mala la idea. La ejecución fue deficiente, pues la reforma se volvió moneda de cambio.

Este artículo pretende demostrar que la reforma político electoral derivada del Pacto por México no introdujo cambios sustantivos en el modelo electoral mexicano.

\section{El sistema electoral mexicano y sus reformas}

Una constante de nuestro sistema electoral ha sido la modificación de las reglas para el acceso a los puestos de elección popular. Esto ha contribuido a la generación de cambios con estabilidad en el sistema político mexicano.

Las reformas constituían mecanismos que utilizaba el poder para proteger el funcionamiento del sistema, es decir, estaban concebidas ya fuera para afian- 
zar el control centralizado, o para flexibilizarlo y darle continuidad y vigencia. Esto particularmente cierto en el plano electoral (Peschard, 2010: 356).

A partir de la década de los cuarenta, particularmente a partir de la reforma de 1946, el sistema electoral mexicano ha tenido más de una decena de reformas. Estas pueden identificarse en cinco periodos generales: 1946 a 1976; 1977 a 1988; 1989 a 1994; 1996 a 2006.

Las dos últimas reformas, 2007-2008 y 2013-2014, serán tratadas como un apartado particular, porque son motivo de un análisis especial.

El periodo de 1946 a 1976, se caracterizó por la consolidación del sistema de partido hegemónico; la universalización del sufragio; la centralización de los organismos electorales con control gubernamental; la autocalificación electoral y el acceso contralado a espacios legislativos para partidos de oposición, a través de la figura de diputado de partido.

La etapa de 1977 a 1988, caracterizada por la liberalización política y la fragmentación del sistema político al término del periodo, tuvo cambios institucionales en materia electoral que dieron lugar a la Ley Federal de Organizaciones Políticas y Procesos Electorales (LFOPPE). Durante este periodo se abrió el sistema de partidos en México, porque estableció el registro condicionado de los partidos y el sistema de representación mixto en la Cámara de Diputados; mantuvo la representación por mayoría relativa y abrió el sistema de representación proporcional y, con ello, el reconocimiento constitucional del pluralismo político. Los partidos políticos también accedieron a la figura de "prerrogativas" para financiar sus actividades electorales y ordinarias.

De 1989 a 1994, se observa la gran transformación en el sistema electoral. Con la reforma constitucional y la promulgación del Código Federal de Instituciones y Procedimientos Electorales en 1989 se modificó la integración y las atribuciones de la autoridad electoral, se suspendió el voto a los partidos políticos en el principal órgano de dirección del IFE. Sin embargo, se mantenía el control a través de la figura del secretario de gobernación como presidente del Consejo General. En 1994 se instrumentó una nueva reforma que introdujo la figura del consejero ciudadano, en el marco de la grave crisis política que vivió el país con la amenaza zapatista en Chiapas y el asesinato del candidato presidencial del PRI, Luis Donaldo Colosio. En general, se modificaron las condiciones de la representación proporcional y se estableció un marco jurídico para garantizar la imparcialidad de las decisiones de la nueva autoridad electoral.

De 1996 a 2006, fue el periodo de la plena autonomía de la autoridad electoral y de la alternancia en el poder. Se modificó la integración de 
la autoridad electoral y se eliminó la intervención del gobierno en la organización de las elecciones. El IFE, si bien tenía en la ley el carácter de autoridad autónoma, a partir de la reforma de 1996 su independencia se hizo una realidad. Se consolidó al Tribunal Electoral, haciéndolo parte del Poder Judicial, otorgándole la calificación de la elección presidencial, convirtiéndolo en la máxima autoridad jurisdiccional y haciendo que sus resoluciones fueran definitivas e inatacables. También se dispuso constitucionalmente el predominio del financiamiento público sobre el privado en los gastos de los partidos políticos y se otorgó el derecho al voto a los mexicanos residentes en el extranjero.

Durante este periodo se produjeron los cambios más importantes del sistema político mexicano. Por primera vez, en la historia moderna del Distrito Federal, se vive una elección directa de sus gobernantes. Deja de existir la figura del regente de la Ciudad, nombrado por el presidente de la República y se establece la de jefe de gobierno electo. Los ciudadanos del Distrito Federal eligen al candidato del PRD, Cuauhtémoc Cárdenas, y con ello se produce la primera alternancia en el centro político del país. Tres años después, como producto de la elección presidencial de 2000, se produce la alternancia en la Presidencia de la República, dando lugar al inicio del gobierno de Vicente Fox, candidato del PAN.

El cerrado resultado de la competida elección presidencial de 2006 trajo como consecuencia una nueva y profunda reforma electoral. El artículo 41 de la Constitución Política de los Estados Unidos Mexicanos se modificó sustancialmente.

\section{La reforma electoral de 2007-2008}

El proceso electoral federal de 2006, uno de los más competidos en la historia de México, evidenció la urgente necesidad de revisar la norma electoral y de establecer límites a la actuación de los partidos, a diversos actores políticos y a particulares interesados e involucrados en la competencia electoral.

Un conjunto de elementos previos al inicio de la elección y durante ella crearon un ambiente de incertidumbre sobre la legalidad de la elección. Por ejemplo, las campañas de los candidatos a la Presidencia fueron agresivas, las televisoras privadas participaron directamente en la contienda, se sumaron abiertamente a descalificar a uno de los candidatos; aunado a esto, la decisión de la autoridad electoral de no difundir las tendencias 
de la votación derivadas del conteo rápido y el cerrado resultado que mostró el PREP, contribuyeron a crear un ambiente de incertidumbre. Es importante recordar que el resultado del cómputo de la elección arrojó una diferencia, entre el primero y el segundo lugar, de $0.56 \%$. Por ello la segunda fuerza, la coalición "Por el Bien de Todos", exigió el recuento de la votación y el Tribunal Electoral del Poder Judicial de la Federación terminó recontando 11839 paquetes electorales y, con ello, ratificó el triunfo del candidato del PAN a la Presidencia. El Tribunal Electoral reconoció la intervención de los particulares con campañas negras en la radio y la televisión a favor del candidato ganador, sin embargo, declaró que no incidieron en los resultados.

En este contexto, se inició una importante negociación para impulsar una reforma electoral que contribuyera a brindar certeza a los resultados de la elección, a reglamentar la intervención de los particulares para no favorecer a un partido político en la radio y la televisión, a regular el uso excesivo de recursos en las campañas electorales; en síntesis, a crear nuevas reglas y las condiciones para que la autoridad electoral garantizará la equidad en la competencia.

La reforma constitucional y legal de 2007-2008 fue profunda y produjo importantes cambios en el sistema electoral. Los cambios y la acción de la autoridad electoral tocaron fibras sensibles de los poderes políticoadministrativos y también de los fácticos.

De manera general, la reforma otorgó a la autoridad electoral nuevas atribuciones para el diseño de un nuevo modelo de comunicación política; fortaleció el modelo de fiscalización de los recursos de los partidos políticos; diseñó un nuevo mecanismo de arbitraje electoral, a fin de hacer más expedita la intervención de la autoridad electoral y estableció nuevas causales para el recuento de la votación, casilla por casilla.

Mucho se ha escrito sobre los temas centrales de la reforma de 20072008, sin embargo es importante hacer un breve resumen que permitirá valorar la siguiente reforma electoral. Los puntos neurálgicos de la reforma fueron:

a) El modelo de comunicación política. El Instituto Federal Electoral se constituyó en la autoridad única para la administración de los tiempos de la radio y la televisión que corresponden al Estado, para uso de los partidos políticos nacionales y de la propia autoridad, bajo un esquema de distribución que pretendió garantizar equidad en el uso de la radio y la televisión, para hacer llegar sus mensajes de promoción a los ciudadanos. Esto fue complementado con la ex- 
plícita prohibición a los partidos políticos y a sus candidatos para comprar o adquirir tiempos en radio y televisión para promoverse o promover a sus candidatos, por sí o por tercera persona. La instrumentación del modelo de comunicación política significó para la autoridad electoral el diseño de un complicado sistema, el SIATE, que garantiza el establecimiento de pautas autorizadas y su transmisión en los tiempos aprobados por la autoridad; que supervisara el cumplimiento de los concesionarios y permisionarios de la radio y la televisión y monitoreara los programas noticiosos. La aplicación del modelo y las medidas instrumentadas por la autoridad electoral tuvieron como respuesta una confrontación con los concesionarios y permisionarios de la radio y la televisión, los cuales incluso adoptaron medidas de desafío directo a las determinaciones del Consejo General. Las reglas se cumplieron. Durante los procesos electorales de 2009 se distribuyeron 14201538 promocionales de los partidos políticos y para 2012 fueron 19840931.

b) Financiamiento a los partidos políticos. La reforma electoral de 2007 2008 modificó el financiamiento sobre la base del modelo de 1996. La premisa fundamental fue que el financiamiento público prevaleciera sobre los otros tipos de financiamiento. Las modalidades de financiamiento son: público, proveniente de la militancia, de simpatizantes; autofinanciamiento y por rendimientos financieros de fondos y fideicomisos. Los cambios fueron los siguientes:

- Se modificó la fórmula para el cálculo del financiamiento público basada en dos variables, padrón electoral, con corte al mes de julio de cada año, y el 65\% del salario mínimo diario vigente en el Distrito Federal. Ambas variables se multiplicaban y el producto de la operación constituía el financiamiento público anual para actividades ordinarias permanentes. Este monto se distribuía 30\% en forma igualitaria a los partidos políticos con representación en el Congreso de la Unión y el 70\% restante según el porcentaje de votación nacional emitida obtenida por cada partido político con representación en alguna de las cámaras del Congreso de la Unión.

- Del monto obtenido por financiamiento público, cada partido debía destinar el 2\% para el desarrollo de actividades específicas; y otro $2 \%$ para actividades de capacitación, promoción y desarrollo del liderazgo de las mujeres. 
- Para gastos de campaña se otorgaba el monto equivalente al $50 \%$ del financiamiento para actividades ordinarias permanentes en elecciones con cambio presidencial y de Congreso de la Unión; para elecciones intermedias (solo renovación de la Cámara de Diputados) se otorgaba el 30\% del mismo rubro.

- Para actividades específicas como entidades de interés público se les otorgaba 3\% del monto entregado para actividades ordinarias permanentes.

Respecto del financiamiento privado las fuentes autorizadas para los partidos políticos fueron: cuotas de la militancia; aportaciones de sus organizaciones sociales; cuotas voluntarias de los candidatos para sus campañas; aportaciones de los simpatizantes; aportaciones de personas físicas o morales que no rebasaran el 5\% del tope de gastos de la campaña presidencial anterior. Las aportaciones privadas, en su conjunto, no podría ser mayor al 10\% del monto de gastos de la campaña presidencial anterior. De esta forma, el modelo de financiamiento garantizó un control más estricto sobre los ingresos de los partidos provenientes de particulares.

El financiamiento solo es una cara de un binomio obligado en los regímenes de financiamiento. La otra es la rendición de cuentas de los partidos sobre el uso y destino del dinero a través de la fiscalización de los recursos. En este rubro también se presentaron importantes innovaciones.

c) Fiscalización de los recursos de los partidos políticos. La innovación fue otorgar atribuciones a un órgano técnico del Consejo General, con autonomía de gestión para fiscalizar los recursos de los partidos políticos. La Unidad de Fiscalización de los Recursos de los Partidos Políticos tuvo las siguientes atribuciones, entre otras: vigilar que los recursos de los partidos provengan de fuentes lícitas, recibir los informes trimestral, anual, de precampaña y de campaña de los partidos y sus candidatos, sin limitación de fiscalización por secreto bancario, fiscal o fiduciario. Fiscalizar los ingresos y los gastos de las organizaciones que pretendan obtener el registro como partidos políticos nacionales; de las agrupaciones nacionales y de las organizaciones de observadores electorales. Así también, es la responsable de los procedimientos de liquidación de los partidos políticos que perdieron su registro. Por otra parte, también le correspondía investigar y presentar los proyectos de resolución de los 
procedimientos administrativos sobre las quejas que se presentaran en materia de la fiscalización.

d) Nuevos sujetos responsables y los procedimientos sancionadores. La inclusión del libro séptimo al Cofipe se destinó a definir a los sujetos regulados, cuya conducta podría ser meritoria de sanciones. También identifica dos procedimientos para conocer y juzgar las faltas a la ley. Uno de ellos, el Procedimiento Ordinario (POS), existía en la ley electoral anterior y el nuevo instrumento fue el procedimiento especial sancionador (PES). La diferencia entre ellos era simple: el POS estaba diseñado para atender quejas genéricas producidas fuera de los procesos electorales, cuya investigación y resolución se producía en un lapso de cuatro meses; y el otro, el PES, para recibir todas las quejas que se presentarán en el desarrollo del proceso electoral y se resolverá en un plazo breve. Lo anterior representó para la autoridad electoral nuevas atribuciones como juez, que naturalmente fue más allá de la acostumbrada facultad administrativa de organizar elecciones. En el desarrollo de las elecciones de 2009 y 2012 se presentaron 455 POS y 2393 PES.

e) Recuento de votos. Derivado del controvertido resultado de la elección presidencial de 2006, se instrumentó un particular procedimiento para las sesiones de cómputo distrital que contribuyera a la certeza del resultado de las elecciones. Dos hipótesis se refieren en el Cofipe, además de las causales tradicionales para realizar el escrutinio y cómputo de las casillas en el Consejo Distrital. La primera señalada en el Código: cuando exista indicio de que la diferencia entre el candidato presunto ganador y el segundo lugar en votación es igual o menor a un punto porcentual se realizará el recuento de votos de la totalidad de las casillas. La segunda, refriere que si al término del cómputo se establece que la diferencia entre el primero y el segundo lugar es igual o menor a un punto porcentual, se deberá realizar el recuento de votos.

IV. La nueva reforma electoral de 2013-2014

Entre el inicio del proceso electoral federal 2011-2012 y antes de que el mismo concluyera, en la Congreso de la Unión se habían presentado un singular número de iniciativas en materia electoral. Entre octubre de 2011 y agosto de 2012 se presentaron en la Cámara de Diputados 69 ini- 
ciativas con propuestas de modificación al artículo 41 de la Constitución de los Estado Unidos Mexicanos y a diversos artículos del Cofipe. ${ }^{4}$

El 2 de diciembre de 2012 en el Castillo de Chapultepec, el Presidente de la República y los presidentes de los partidos Acción Nacional, de la Revolución Democrática y Revolucionario Institucional firmaron el Pacto por México. Éste se conformó en tres ejes rectores: fortalecimiento del Estado Mexicano; democratización de la economía y la política, así como la ampliación y aplicación eficaz de los derechos sociales, y participación de los ciudadanos como actores fundamentales en el diseño, ejecución y evaluación de las políticas públicas. Además, el acuerdo estaba integrado por cinco puntos básicos, desglosados en asuntos de atención particular: a) sociedad de derechos y libertades; $b$ ) crecimiento económico, empleo y competitividad; $c$ ) seguridad y justicia; $d$ ) transparencia, rendición de cuentas y combate a la corrupción, y e) gobernabilidad democrática.

Los compromisos 89 y 90 fueron los centrales para convenir la reforma electoral. El compromiso 89 buscaba establecer un marco jurídico estable y claro a la actuación de los partidos políticos en tiempos electorales y no electorales, traducido en una ley de partidos.

En tanto, el compromiso 90 delineó los elementos que debía considerar la reforma electoral. Consideraba la reducción y la transparencia de los gastos de los partidos políticos; la disminución en el monto de los topes de campaña y la incorporación de causales de nulidad por rebase en topes de campaña, así como a la utilización de recursos al margen de las normas establecidas por el órgano electoral; la compra de cobertura informativa en cualquiera de las modalidades periodísticas, considerando sancionar al medio involucrado; la revisión de los tiempos oficiales en radio y televisión para impulsar la cultura de debate político y una racionalización del uso de los anuncios publicitarios. Así también, prohibir el uso y la entrega de utilitarios de promoción electoral, tales como materiales plásticos, materiales textiles, despensas y materiales de construcción; fortalecer la legislación para evitar el uso de esquemas financieros y/o recursos de origen ilícito con el propósito de inducir y coaccionar el voto, y crear una autoridad electoral de carácter nacional y una legislación única, que se encargue tanto de las elecciones federales, como de las estatales y municipales. ${ }^{5}$

${ }^{4}$ Sistema de Información Legislativa. Secretaría de Gobernación. Iniciativas presentadas en la Cámara de Diputados de la LXI Legislatura en las sesiones del 29 de agosto de 2009 al 31 de agosto de 2012.

Presidencia de la República. Pacto por México, http://www.presidencia.gob.mx/wpcontent/uploads/2012/12/Pacto-Por-M\%C3\%A9xico-TODOS-los-acuerdos.pdf. 
El proceso legislativo para la construcción de los acuerdos no fue sencillo. El Dictamen de las Comisiones Unidas de Puntos Constitucionales, de Gobernación, de Reforma del Estado y de Estudios Legislativos Segunda, sobre la Constitución en materia político electoral, da cuenta de por lo menos la presentación de 56 iniciativas. ${ }^{6}$ Sin embargo, para la preparación del proyecto de reforma constitucional se consideraron dos iniciativas: una presentada por senadores de los Grupos Parlamentarios del Partido Acción Nacional y del Partido de la Revolución Democrática; y la iniciativa promovida por senadores y diputados de los Grupos Parlamentarios del Partido Acción Nacional en las Cámaras de Diputados y de Senadores.

La reforma constitucional a diversos artículos fue aprobada el 22 de enero de 2014 y publicada en el Diario Oficial de la Federación el 10 de febrero del mismo año. El decreto reformó 25 artículos, de los cuales seis corresponden a la materia electoral en sentido estricto.

La reforma al artículo 41 señala que la función estatal de organizar las elecciones se realiza a través del Instituto Nacional Electoral y de los organismos públicos locales. La autoridad constitucional, ahora denominada Instituto Nacional Electoral (INE), mantiene las características que tuvo el IFE: organismo público autónomo, dotado de personalidad jurídica, patrimonio propio, integrado por el Poder Legislativo, los partidos políticos y los ciudadanos; pero se agrega a sus principios rectores de certeza, legalidad, independencia, imparcialidad y objetividad, la máxima publicidad. Cambia la integración del Consejo General, máximo órgano de dirección. Ahora está integrado por un presidente y por diez consejeros electorales, quienes durarán nueve años sin posibilidad de reelección; se mantiene la presencia de consejeros del Poder Legislativo, uno por cada fracción parlamentaria, y un representante por cada partido político con registro nacional.

El método de selección para elegir al presidente y a los nueve consejeros electorales resultó una verdadera novedad. La responsabilidad de revisar el cumplimientos de requisitos legales y la idoneidad para el cargo se dejó en un Comité Técnico de evaluación integrado por siete personas nombradas de la siguiente manera: tres por el órgano de dirección de la Cámara de Diputados, dos por la Comisión Nacional de Derechos Humanos y dos por el organismo garante establecido en el artículo sexto de la Constitución. El Comité será responsable de integrar listas con cinco personas por cargo vacante y entregarlo al órgano de dirección de

${ }^{6}$ Considera todas las iniciativas en materia político-electoral presentadas en las LX y LXI Legislaturas, así como en la Legislatura LXII. 
la Cámara de Diputados para la construcción de acuerdos y pasarlo al pleno para su votación. En caso de no llegar a acuerdos o no alcanzar la votación requerida, se procedería al método de insaculación sobre las quintetas integradas por el Comité; ante el fracaso de lo anterior, la Suprema Corte de Justicia de la Nación realizaría la insaculación en sesión pública para la designación.

Respecto de la organización de las elecciones, al Instituto Nacional Electoral le corresponde para procesos electorales federales y locales: la capacitación electoral, la geografía electoral, el padrón y la lista de electores, la ubicación de casillas y designación de funcionarios, las reglas y lineamientos para resultados preliminares, encuestas o sondeos de opinión pública, observación electoral, conteos rápidos, impresión de documentos y producción de materiales. Además, exclusivo para los procesos federales: los derechos y el acceso a las prerrogativas de los partidos políticos y sus candidatos, la preparación de la jornada electoral, la impresión de documentos y la producción de materiales, el escrutinio y cómputo, la declaración de validez y el otorgamiento de constancias en las elecciones de diputados y senadores, así como el cómputo de la elección de presidente. Además, podrá asumir mediante convenio la organización de procesos electorales locales, a petición la organización de las elecciones de los dirigentes de los partidos políticos, con cargo a sus prerrogativas.

El Consejo General, con el apoyo de un órgano técnico, realizará la fiscalización de las finanzas de los partidos políticos y de las campañas.

Las elecciones locales estarán a cargo de organismos públicos locales que tienen a su cargo el derechos y el acceso a las prerrogativas de los partidos políticos y sus candidatos, la educación cívica, la preparación de la jornada electoral, la impresión de documentos y producción de materiales, el escrutinio y cómputos de las elecciones, la declaración de validez y el otorgamiento de la constancia de la elección local, el cómputo de la elección de gobernador, resultados preliminares, encuestas o sondeos de opinión, observadores electorales, conteos rápidos conforme las reglas y lineamientos del INE.

Con el voto mínimo de ocho consejeros del Consejo General del INE se podrá:

- Asumir la realización de las actividades de la función electoral correspondientes a los organismos locales;

- Delegar en esos órganos atribuciones del órgano nacional referidas para proceso federales y locales.

- Atraer cualquier asunto de la competencia del órgano local para sentar un criterio de interpretación. 
El Consejo General del INE designa y remueve a los consejeros electorales del órgano superior de los OPLE. Además regula el servicio profesional electoral nacional, que comprende a los servidores públicos de los órganos ejecutivos y técnicos del INE y de los organismos electorales locales.

Respecto del sistema de medios de impugnación, el artículo 41 refiere que la ley establecerá el sistema de nulidades de las elecciones federales o locales por violaciones graves, dolosas y determinantes en caso de que:

- Se exceda el gasto de campaña autorizado en un 5\% del monto autorizado.

- Se compre cobertura informativa o tiempos en radio y televisión.

- Se reciban o utilicen recursos de procedencia ilícita o recursos públicos en las campañas.

Las violaciones deberán acreditarse objetiva y materialmente y se presumirá que son determinantes cuando la diferencia entre la votación obtenida entre el primero y el segundo lugar sea menor al 5\%. En caso de nulidad se convocará a elección extraordinaria y no podrá participar la persona sancionada. Sobre los partidos políticos, el artículo 41 constitucional aumenta el requisito de la votación total emitida para mantener el registro al $3 \%$.

El 15 de mayo, después de un largo proceso de negociación entre las fracciones parlamentarias del Congreso de la Unión, se aprobaron las leyes para regular los procesos electorales y fueron publicadas en el Diario Oficial de la Federación el 23 de mayo de 2014: la Ley General de Instituciones y Procedimientos Electorales (LGIPE) y la Ley de Partidos Políticos.

El primer cambio respecto del abrogado Cofipe y las nuevas leyes en la materia fue separar las reglas que normaban a los partidos políticos y las correspondientes a las instituciones y procedimientos electorales responsables de organizar las elecciones. Los cambios particulares respecto de los temas neurálgicos de la reforma de 2007-2008 son los siguientes.

\section{Modelo de comunicación política}

La LGIPE mantiene casi sin cambios el modelo de comunicación política de la Reforma electoral 2007-2008. Las modificaciones son dos. Primero, se agrupa en un solo apartado a los partidos políticos y las coaliciones 
en todo lo relacionado a los tiempos de la radio y la televisión; como se puede observar en que el Capítulo 1 del Acceso a Radio y Televisión, del Título Segundo, de las Prerrogativas de los Partidos Políticos, a diferencia de lo que sucedía en el Cofipe; donde esas normas estaban dispersas

En segundo lugar, dos elementos nuevos se presentan en los artículos 181 y 186. En el primero, se eliminó el derecho de los partidos políticos al programa mensual con duración de cinco minutos fuera de los periodos de precampaña y campaña, en cada estación de radio y televisión. Respecto del segundo artículo, establece los plazos que deberá contemplar el reglamento de radio y televisión:

- Cinco días para la entrega, sustitución o puesta a disposición a los concesionarios de las órdenes de transmisión y los materiales durante periodo ordinarios.

- Tres días para la entrega, sustitución o puesta a disposición a los concesionarios de las órdenes de transmisión y los materiales desde el inicio de las precampañas y hasta la jornada electoral.

- Pero también, la autoridad electoral puede reducir los plazos cuando sea inviable técnicamente, así también deberá garantizar la recepción de materiales las 24 horas del día todos los días del año.

- La entrega de las órdenes de transmisión y notificación a los concesionarios se realizarán vía electrónica, personal o satelital.

Ambos cambios, desde nuestro punto de vista, son pertinentes. Sobre la eliminación del programa de cinco minutos, se debe reconocer que no era esa la mejor manera de presentar las propuestas políticas de los partidos. Respecto de las normas para la administración de los promocionales, debe reconocerse que estando en la ley tienen mayor fuerza política.

Es indudable que el modelo de comunicación instrumentado por el IFE logró cumplir las expectativas de los actores políticos, no obstante las diferencias que se tuvieron con los empresarios del ramo y su renuencia a cumplir lo establecido por ley de 2008.

\section{Cómputos distritales: se mantiene voto por voto}

La experiencia del cómputo distrital con recuento de votos en los procesos electorales 2009 y 2012, derivado de la aplicación de la reforma electoral de 2008 y las medidas adoptadas por el Instituto Federal Electo- 
ral para la funcionalidad de las sesiones especiales, ${ }^{7}$ permitieron brindar certeza sobre los resultados electorales y concluir a tiempo, respetando lo establecido en el Cofipe. Seguramente, esto contribuyó para que este tema no fuera modificado en lo sustantivo en la Ley General de Instituciones y Procedimientos Electorales.

Dos novedades en el tema se ubican una en el artículo 309, al que se le incorpora un párrafo 2, que faculta al Consejo General para determinar la participación de personal auxiliar de los consejos distritales para el recuento de votos, y la otra en el artículo 320 sobre el procedimiento del cómputo para la elección de senadores en el consejo local de cada entidad federativa. En el Cofipe el artículo correspondiente (304) solo constaba de cuatro incisos que describían el procedimiento, que data del Cofipe de 1994.

Ahora se incorpora en la ley siete incisos más que describen el procedimiento para el recuento de votos por medio de un método aleatorio, que aprobará el Consejo General, cuando exista una diferencia igual o menor a un punto porcentual. Para esta hipótesis sólo se considerarán las casillas que no se hubieran recontado en los consejos distritales.

Es importante recordar que nunca antes, en ningún proceso electoral se recontaron tantos paquetes electorales como el que se realizó en las sesiones de cómputo distrital de la elección de 2012. La experiencia de los cómputos en esa elección colocó a los consejos distritales, que tuvieron recuento total de votos, en un escenario de riesgo para cumplir con los tiempos establecidos en la ley para su conclusión. En 2009 se recontaron el $30.6 \%$ de los paquetes electorales, en tanto que para 2012 el recuento de paquetes de la elección de presidente fue de $54.7 \%$, en la correspondiente a senadores fue de $57.4 \%$ y de diputados el $56.7 \%{ }^{8}$

7 Para el proceso electoral federal 2009 el IFE aprobó dos acuerdos (CG185/2009 del 15 de mayo y CG335/2009 del 29 de junio) que previeron acciones para el desarrollo de las sesiones de cómputo distrital y criterios para atender los asuntos relevantes. Sobre la experiencia del proceso electoral anterior, en 2012 el Consejo General acordó reformar el Reglamento de Sesiones de los Consejos Locales y Distritales agregando un capítulo para las sesiones de cómputo distrital. Adicional a esto, también se aprobaron lineamientos específicos (CG244/2012, del 25 de abril), apelados ante la Sala Superior del TEPJF por el PRI y la coalición Movimiento Progresista.

8 Cálculos elaborados con los datos publicados en el Sistema de Consulta de la Estadística de las Elecciones Federales 2011-2012. Atlas de Resultados Electorales Federales 1991-2012, Recuento de Votos, en http://siceef.ife.org.mx/pef2012/SICEEF2012.html\#. 


\section{Financiamiento}

Se mantiene el modelo de financiamiento y la fórmula de cálculo: el financiamiento público prevalece sobre el privado para los partidos políticos nacionales y lo novedoso es que también para los partidos locales.

\section{Fiscalización a los recursos de los partidos políticos}

Se aprobaron cambios sustantivos a lo establecido en el Cofipe. La Ley General de Instituciones y Procedimientos Electorales conserva en el Consejo General la facultad de fiscalizar los ingresos y gastos de los partidos políticos nacionales y locales, así como de los candidatos a las elecciones federales y locales. Lo anterior, lo hará a través de la Comisión de Fiscalización, integrada por cinco consejeros electorales del Consejo General; ésta contará con el apoyo de una Unidad Técnica de Fiscalización. Las facultades de la Unidad de Fiscalización de los Recursos de los Partidos Políticos fueron trasladadas a la Comisión de Fiscalización del Consejo General, quien además revisará las funciones y acciones de la nueva Unidad Técnica de Fiscalización. A fin de garantizar la certeza y legalidad en el desarrollo de las funciones fiscalizadoras de la Unidad, el párrafo 3 del artículo 192 señala que las facultades de la comisión serán ejercidas respetando la plena independencia técnica de la Unidad y en el mismo sentido, se prevé en el párrafo 4 que los integrantes de la Comisión no podrán intervenir en los trabajos de la Unidad de forma independiente.

Cabe recordar que el PRD propuso un proyecto de acuerdo al Consejo General para el inicio de un procedimiento extraordinario de fiscalización a los gastos de campaña de la elección de presidente de los Estados Unidos Mexicanos de la coalición Compromiso por México. Los consejeros no aprobaron el proyecto, pero determinaron analizar el tema en el grupo de trabajo integrado por consejeros electorales, para dar seguimiento a los procedimientos de revisión y resolución de informes de precampaña y campaña de los partidos políticos nacionales y coaliciones, correspondientes al proceso electoral. El PRD no desistió en su iniciativa, así entregó un nuevo Proyecto de Acuerdo, para el procedimiento extraordinario de fiscalización ahora considerando a los partidos políticos y a las coaliciones electorales. Finalmente, el Consejo General aprobó un Acuerdo para la fiscalización anticipada. ${ }^{9}$ En el calendario se respetaron

9 IFE. Acuerdo CG301/2012. Acuerdo del Consejo General del Instituto Federal Electoral, por el que se aprueba el Programa de Fiscalización a los partidos políticos y 
los tiempos de los partidos políticos para la presentación de sus informes, aclaraciones y confrontas con la autoridad electoral. Sin embargo, al conocer los resultados del Dictamen, los partidos políticos integrantes de la Coalición Movimiento Progresista iniciaron una campaña en contra del método de revisión y fiscalización del gasto.

Uno de los temas de mayor polémica en ese momento fue el prorrateo. Éste es un mecanismo de distribución del gasto de los partidos entre sus campañas electorales y candidatos. El concepto y su procedimiento se encontraban en el artículo 177 del Reglamento de Fiscalización. ${ }^{10}$ El 6 de febrero de 2013, en la sesión del Consejo General en el marco de la presentación del Dictamen y el proyecto de Resolución, fue rechazado éste, bajo el argumento que debía incorporar la definición del concepto de campaña beneficiada, y motivar adecuadamente los elementos y razones para acreditar el beneficio de las campañas relacionadas con una misma erogación y se determinó presentar nuevamente el Dictamen y el Proyecto de Resolución hasta julio de 2013, de acuerdo con el artículo 84 del Cofipe. ${ }^{11}$

coaliciones propuesto por la Unidad de Fiscalización, respecto de los ingresos y gastos de campaña, relativos a los Candidatos a la Presidencia de los Estados Unidos Mexicanos para el proceso electoral federal 2011-2012 y se aprueba la presentación anticipada del Dictamen consolidado y proyecto de resolución de la misma elección presidencial. http://www.ine.mx/docs/IFE-v2/DS/DS-CG/DS-SesionesCG/CG-acuerdos/2012/Mayo/ CGext201205-16/CGe160512ap9.pdf.

10 El artículo 177 del Reglamento de Fiscalización señalaba:

1. Los gastos de campaña centralizados y las erogaciones que involucren dos o más campañas de un partido o una coalición de cualquier tipo, deberán efectuarse con recursos provenientes de cuentas CBCEN o CBE del partido, y serán distribuidos o prorrateados entre las distintas campañas de la forma siguiente:

a) Por lo menos el cincuenta por ciento del valor de dichas erogaciones deberá ser distribuido o prorrateado de manera igualitaria entre todas las campañas del partido o coalición beneficiadas por tales erogaciones, debiendo entenderse como la distribución o prorrateo que resulte de dividir el total prorrateable en partes idénticas entre las campañas beneficiadas con el gasto, lo que se traduce en la asignación de montos iguales a los candidatos promovidos, $\mathrm{y}$

b) El cincuenta por ciento restante de su valor será distribuido o prorrateado de acuerdo con los criterios y bases que cada partido o coalición adopte, en concordancia con las campañas beneficiadas indicadas en el inciso a) del presente artículo. Dichos criterios deberán hacerse del conocimiento de la Unidad de Fiscalización al momento de la presentación de los informes de campaña, y por ningún motivo podrán ser modificados con posterioridad. El partido u órgano de finanzas de la coalición deberá especificar los porcentajes de distribución aplicados a cada campaña.

11 IFE. Acuerdo CG49/2013. Acuerdo del Consejo General del Instituto Federal Electoral, por el que se ordena la devolución del "Dictamen Consolidado de la Unidad de 
Finalmente, el 16 de julio de 2013, el Consejo General recibió el Dictamen de los resultados de la revisión y auditoría de los gastos de los partidos políticos en todas las campañas electorales. Todos los partidos políticos fueron sancionados. El ejercicio de fiscalización en la magnitud que realizó el IFE para una elección con cambios de los poderes Ejecutivo y Legislativo, nunca antes se había realizado.

Por ello, no es casual que tanto en la LGIPE como en la LPP se tuviera particular cuidado en modificar el modelo de fiscalización de los recursos de los partidos políticos.

En el actual modelo de fiscalización el prorrateo no estará más en el ámbito reglamentario y los partidos no podrán determinar la distribución del gasto entre sus candidatos derivados de la promoción a presidente, senadores y diputados, porque éste se ubica en el artículo 83 de la LGPP. Así también se define el concepto de gasto genérico de campaña y de candidato beneficiado.

Otro elemento novedoso en el modelo lo constituye la revisión y fiscalización simultánea al desarrollo de la precampaña y campaña. Los informes de precampaña se presentarán a más tardar dentro de los diez días siguientes a su conclusión. Para las campañas se presentarán informes de gastos por periodos de 30 días a partir del inicio de la campaña. Así también se indican plazos de entrega de resultados de la revisión, análisis de la información, elaboración del dictamen y proyecto de resolución, así como para su aprobación. ${ }^{12}$ Los sujetos fiscalizables son:

- Partidos políticos federales y locales.

- Coaliciones federales y locales.

- Candidatos a cargos de elección popular federal y local.

- Aspirantes y candidatos Independientes federales y locales.

- Agrupaciones políticas nacionales.

- Organizaciones de ciudadanos que pretendan constituir un partido político nacional.

- Organizaciones de observadores electorales a nivel federal.

Fiscalización de los Recursos de los Partidos Políticos y Proyecto de Resolución del Consejo General del instituto federal electoral respecto de las Irregularidades encontradas en el dictamen consolidado de La revisión anticipada de los informes de ingresos y gastos de Campaña, relativos a los candidatos a la presidencia de los Estados unidos mexicanos para el proceso electoral federal 2011-2012", a la Unidad de Fiscalización de los Recursos de los Partidos Políticos.

12 Véase artículo 80 de la Ley General de Partidos Políticos. 
La dimensión de la tarea que realizará la Comisión de Fiscalización, con el auxilio de la Unidad Técnica de Fiscalización, será inmensa. Sólo para el próximo año, 2015, en 18 entidades se tendrán elecciones, 9 gobernadores, 387 diputaciones de mayoría relativa locales y 1009 ayuntamientos (sin considerar que los ayuntamientos se conforman por un presidente municipal, síndicos y regidores, por lo que la elección se realiza por planilla); además de la elección federal de 300 diputados de mayoría relativa; en total se considera aproximadamente 1705 cargos.

\section{Los organismos públicos locales}

La reforma constitucional al artículo 116 delinea los contenidos que deberán considerar las leyes electorales de las entidades federativas para alcanzar la concordancia legislativa en los rubros correspondientes y detallados en el artículo 41 constitucional.

El artículo 98 de la LGIPE refiere que la integración es similar a la que ya mantienen los institutos locales: un consejo general integrado por seis consejeros electorales con derecho a voz y voto, que serán designados por el Consejo General del INE, un secretario ejecutivo y representantes de los partidos políticos nacionales y estatales con derecho a voz.

Los OPLE son autoridad en la materia electoral, tienen personalidad jurídica y patrimonios propios y gozan de autonomía en su funcionamiento e independencia en sus decisiones. Su patrimonio está conformado por bienes inmuebles y muebles destinados al cumplimiento de sus funciones así como por las partidas que anualmente se señalen en el presupuesto de cada entidad federativa para la organización de las elecciones y el financiamiento de los partidos políticos. ${ }^{13}$

La ley también establece, de manera muy detallada, el proceso de elección de los consejeros electorales para la integración de los OPLE, los supuestos de vacancias y también el procedimiento de remoción.

Para la coordinación y relación del INE con los OPLE se presentan dos órganos: Comisión de Vinculación con los Organismos Públicos Locales y la Unidad de Vinculación con los Organismos Públicos Locales, adscrita a la Secretaría Ejecutiva del INE. El primero está integrado por consejeros electorales del Consejo General. El segundo es el responsable directo de la vinculación, coordinación y supervisión del desarrollo de actividades encaminadas a la organización de las elecciones.

13 Artículo 99, párrafo 2, de la Ley General de Instituciones y Procedimientos Electorales. 
La idea original expresada en el Pacto por México respecto a una sola autoridad electoral nacional no se pudo concretar. Fue ésta una demanda reiterada durante el desarrollo de procesos electorales locales, bajo el argumento de que existía intervención de autoridades gubernamentales, compra de voto en especie, manejo discrecional de recursos para favorecer a los candidatos oficiales, etcétera. Lo cierto es que se presentaron casos de autoridades electorales con dificultades para regular las contiendas y hasta para brindar información sobre las tendencias de votación al final de la jornada electoral, derivado de problemas operativos.

Sin embargo, lo que se ha aprobado en la Constitución y en la ley es la configuración de un órgano electoral nacional, el INE, cuyo deber es coordinar y supervisar a 32 órganos locales que no dependen de él directamente, porque tienen personalidad jurídica y son autónomos, aunque paradójicamente estén obligados a acatar las disposiciones de la autoridad federal. Sin embargo, está previsto en la LGIPE la posibilidad de que las autoridades electorales, federal y locales, puedan firmar convenios para la asumir la organización de los procesos electorales locales.

Entre las atribuciones del INE, la ley considera tres conceptos claves para la relación los OPLE: asunción, atracción y delegación. La asunción es la atribución de asumir directamente todas las actividades propias de la función electoral de los OPLE. ${ }^{14}$ La asunción de la competencia de una elección local será procedente si se presentan dos supuesto: $a$ ) existencia de factores que impiden la organización pacífica de las elecciones, afecten los principios constitucionales y la equidad; $b$ ) injerencia o intromisión comprobable de algunos de los poderes públicos que afectan el desarrollo de las etapas del proceso electoral. La asunción se iniciará a petición de parte, avalada por la mayoría de los consejeros electorales, y se presentará hasta antes del inicio del proceso electoral, también denominada asunción total.

La asunción también puede ser parcial, ${ }^{15}$ solo para alguna actividad que corresponda al órgano local; ésta se podrá presentar en cualquier momento del proceso

La facultad de delegación tiene carácter excepcional. Se trata de las tareas que corresponden al INE para la organización de la elección local: capacitación electoral, geografía electoral y distritación, padrón y lista de electores, ubicación de casillas y designación de funcionarios, resultados preliminares, encuestas, sondeos de opinión, observadores electorales,

14 Artículo 120 de la Ley General de Instituciones y Procedimientos Electorales.

15 Artículo 123, ibidem. 
conteos rápidos, impresión de documentos y materiales, fiscalización de ingresos y egresos de los partidos políticos. El Consejo General del INE valorará la posibilidad antes del inicio del proceso electoral.

La facultad de atracción ${ }^{16}$ es para conocimiento de algún asunto de la competencia de los OPLE, en el que se requiera sentar un criterio de interpretación o por su trascendencia. El párrafo 3 del artículo 124 refiere la trascendencia como:

3. Se considera que una cuestión es trascendente cuando la naturaleza intrínseca del asunto permita que éste revista un interés superlativo reflejado en la gravedad del tema, es decir, en la posible afectación o alteración del desarrollo del proceso electoral o de los principios de la función electoral local.

El Consejo General valorará si es el asunto es novedoso y si el alcance de la resolución es trascendente para la sociedad o en la función electoral.

\section{Elecciones concurrentes}

Desde 1997 y hasta 2006 el IFE siempre convino la celebración de elecciones concurrentes mediante convenios que permitieron la preparación y organización de la jornada electoral en el ámbito federal y local. En 1997 firmó convenios de apoyo y colaboración con las autoridades electorales de siete entidades: Campeche, Colima, Distrito Federal, Guanajuato, Nuevo León, Querétaro y San Luis Potosí. En junio de 2015, 18 entidades federativas celebrarán elecciones locales simultáneamente con la federal. De ellas, nueve tendrán elecciones completas, elegirán gobernador, congreso local y ayuntamientos.

A partir de la reforma de 2007, con la modificación a la fracción IV del artículo 116, para que la jornada electoral se realizara en la misma fecha que la elección federal, se contribuyó al incremento de entidades con elección concurrente con la federal. En 2009 se realizó elección concurrente con 11 entidades federativas, y para la elección de 2012 la autoridad electoral federal firmó convenios de apoyo y colaboración con 16 autoridades locales, de las cuales una no fue coincidente con la jornada electoral federal.

16 Artículo 124, ibidem. 
La concurrencia es un factor que contribuye a lograr mayor participación de los ciudadanos en las urnas. Como refiere Ávila Eggleton, ${ }^{17}$ en su modelo de correlación, la participación ciudadana se incrementa en este tipo de procesos. En su estudio identifica dos factores que inciden en el incremento de la participación. Uno es la concurrencia como tal. En el periodo histórico analizado, 1977 a 2012, muestra que las entidades con elección concurrente tuvieron una mayor participación que aquellas que solo tuvieron elección federal. El otro factor es el tipo de elección, ya sea presidencial o intermedia, en entidades con elección concurrente. El resultado evidencia que la participación en las elecciones intermedias es mayor que en las presidenciales. De cualquier forma, se puede derivar que la elección concurrente incide en la participación ciudadana; aunque se desconozca los factores que motivan esta conducta.

Por otra parte, la importancia de homologar la votación en un solo día, seguramente también trae beneficios a la autoridad electoral, pero por el momento este es un tema poco explorado en la administración electoral.

Lo importante del análisis es la relación entre concurrencia de elecciones y la participación ciudadana, trascendente porque se tienen datos duros de la baja participación en elecciones. Este tema no ha sido abordado por los actores políticos, cuya responsabilidad estatal es buscar mecanismos que contribuyan a modificar la conducta ciudadana, para orientarla hacia una cultura de mayor participación en los asuntos públicos, propia de una sociedad democrática. Éste es finalmente nuestro gran tema y sigue pendiente.

\section{Bibliografía}

Alarcón Olguín, Víctor et al., Elecciones 2012. Evaluación e implicaciones políticas, México, UAM, 2012.

Ávila Eggleton, Marcela, Concurrencia y participación. Efecto de las Reformas en los procesos electorales, Ponencia para el Congreso 2014 de la Asociación de Estudios Latinoamericanos, Chicago, 21-24 de mayo de 2014.

BeCERra, Ricardo et al., La mecánica del cambio político en México. Elecciones, partidos y reformas, 3a. ed., México, Cal y Arena, 2005.

${ }_{17}$ Concurrencia y participación. Efecto de las Reformas en los procesos electorales, 2014. 
Bowler, Shaun y Donovan, Todd, The Limits of Electoral Reform, Oxford University Press, 2013.

Córdova Vianello, Lorenzo, "El financiamiento a los partidos políticos en México", en Gutiérrez, Pablo y Zovatto, Daniel (coords.), Financiamiento de los partidos politicos en América Latina, México, IDEA Internacional-OEA-UNAM, Instituto de Investigaciones Jurídicas, 2011.

_-_, 2014, "Sistema electoral y sistema de partidos. Pluralismo político en las reformas constitucionales en materia electoral", en CASAR, María Amparo y MARván, Ignacio (coords.), Reformar sin mayorías. La dinámica del cambio constitucional en México: 1997-2012, México, Taurus.

___, "La reforma electoral de 2007-2008 cuatro años después. Apuntes para un balance de su instrumentación", Revista Mexicana Derecho Electoral, México, núm. 1, enero-junio de 2012.

-_- , Voto razonado que formula el Consejero Electoral Lorenzo Códova Vianello respecto del Dictamen y Proyecto de Resolución Presentados por la Unidad de Fiscalización de los Recursos de los Partidos Políticos por lo que hace a los Informes sobre el origen, monto y destino de los recursos de las campañas federales electorales, correspondientes al Proceso Electoral Federal 2011-2012, en http://www.ine.mx/docs/IFE-v2/DS/DSCG/DS-SesionesCG/CG-resoluciones/2013/Julio/CGext201307-15_01/ CGe150713rp4_x2.pdf.

- - - y Salazar Ugarte, Pedro, Estudios sobre la Reforma Electoral 2007. Hacia un nuevo modelo, México, TEPJF.

Cristalinas, Alfredo, "Fiscalización del IFE a partidos políticos nacionales”, Revista Mexicana de Derecho Electoral, México, núm. 1, enerojunio de 2012.

Decreto por el que se reforman, adicionan y derogan diversas disposiciones de la Constitución Política de los Estados Unidos Mexicanos, en materia política-electoral, Diario Oficial de la Federación, 10 de febrero de 2014.

Instituto Federal Electoral, 20 Años, México, IFE, 2010, p. 524.

- - - Acuerdos y resoluciones del Consejo General, http://www.ine. $m x /$ portal/site/ifev2/.

- - - Código Federal de Instituciones y Procedimientos Electorales, México, IFE, 2011.

- - - Constitución de los Estados Unidos Mexicanos. Ordenamientos Electorales, 2a. ed., México, IFE, 2008, t. I. 
- - , Informe General sobre la Implementación de la Reforma Electoral, durante el Proceso Electoral 2008-2009, México, IFE, 2010.

- - , Memoria del Proceso Electoral Federal 2008-2009, México, IFE, 2010.

-_-, Memoria del Proceso Electoral Federal 2011-2012, México, IFE, 2013.

Ley General de Instituciones y Procedimientos Electorales, Diario Oficial de la Federación, 23 de mayo de 2014.

Ley General de Partidos Políticos, Diario Oficial de la Federación, 23 de mayo de 2014.

Molinar Horcasitas, Juan, El tiempo de la legitimidad. Elecciones, autoritarismo y democracia en México, México, Cal y Arena, 1993.

PESCHARD, Jacqueline, "De la conducción gubernamental al control parlamentario: 30 años de reformas electorales", en LoAeza, Soledad y Prud'Homme, Jean-Francois, Los grandes problemas de México, tomo $X I V$, Instituciones y procesos políticos, México, El Colegio de México.

Renwick, Alan, The Politics of Electoral Reform. Changing the Rules of Democracy, Nueva York, Cambridge University Press, 2010.

Secretaría de Gobernación, Sistema de Información Legislativa, http://sil. gobernacion.gob. $m x /$ portal.

Tuñón, Enriqueta, Por fin ya podemos elegir y ser electas. El sufragio femenino en México 1935-1953, México, INAH-Plaza y Valdés, 2002.

Woldenberg, José, Historia mínima de la transición democrática en México, México, El Colegio de México, 2012. 